\title{
LA TRADICIÓN GRAMATICAL Y EL SISTEMA VERBAL LA ENSEÑANZA DE LA TEMPORALIDAD
}

Fermín Martos Eliche

Universidad de Granada

http://dx.doi.org/10.18778/8220-201-4.18

\section{Resumen}

El objetivo principal de este trabajo se fundamenta en el creciente interés de estudiar las implicaciones extralingüísticas del tiempo. Se hará un recorrido por la tradición gramatical para escudriñar las actuales tendencias sobre la concepción del binomio tiempo-aspecto para intentar renovar algunas ideas de gramáticos como Gómez Hermosilla y su obra Principios de Gramática General de 1835. Apuntar hacia el futuro dando importancia a estas enseñanzas tradicionales (gérmenes de las actuales teorías) para la enseñanza de la temporalidad en las clases de ELE (Español Lengua Extranjera) será nuestro trayecto final.

Palabras clave: Tradición gramatical, verbo, temporalidad, ELE.

\section{1.}

\section{Introducción}

Hemos de tener en cuenta, en primera instancia, una fecha importante en la tradición gramatical: 1847. Es la fecha elegida por las dos obras de referencia de estudio de la tradición española en lingüística: la de J. J. Gómez Asencio (Gramática y categorías verbales en la tradición española (1771-1847)) y la de M. L. Calero Vaquera (Historia de la gramática española (1847-1920)). Ambos 
escogen la fecha de la Gramática de Andrés Bello como fecha de transición, considerando el inicio de la tradición en 1771 (fecha de la publicación de la primera gramática de la $R A E$ ) y el fin en 1920 (fecha de la publicación de la obra de R. Lenz: La oración y sus partes). Si situamos 1847 como fecha central, podríamos resumir las aportaciones antes y después de esa fecha y la propia de 1847 (la de Bello).

Antes de 1847 el verbo, junto al sustantivo, conserva la preeminencia sobre las demás clases de palabras. Si hasta entonces se definía el verbo en términos morfológicos o morfosintácticos, ahora se da preferencia al criterio semántico y sobre todo al lógico-objetivo. Tal preeminencia viene motivada por las tendencias universalistas que recorrían Europa. Así, en general, el verbo es la palabra que significa "hacer" (acción), "padecer" (pasión), o "ser" (existencia). La dificultad estaba en encontrar un único criterio para definir el verbo (como existía para el sustantivo, "sustancia", y el adjetivo, "cualidad") por sus variadas posibilidades semánticas. No se dieron cuenta, apegados como estaban a la tradición, de que el semántico no era el criterio adecuado para definir al verbo y a la mayoría de clases de palabras. Recogemos, a modo de ejemplo, una definición que muestra la preeminencia del criterio semántico, la de la GRAE:

El verbo es una parte principal de la oración que sirve para significar la esencia, la existencia, la acción, pasión y afirmación de todas las cosas animadas y el ejercicio de cualquiera facultad que tienen las cosas o se les atribuye (GRAE, 1771:57).

Algunos autores, entre ellos, Noboa, a quien citamos a continuación se dieron cuenta de la parcialidad de este tipo de definiciones (aunque sin reparar en dos diferencias básicas: la que hay entre lenguaje y metalenguaje y la que se establece entre "nombrar" y "predicar"):

Siendo una palabra de naturaleza tan distinta del nombre, hay que distinguirla con un nombre, y por eso su naturaleza no queda bien explicada. Pues, decir que el verbo significa ser, 
afirmación, existencia, movimiento, etc. es como decir que el verbo tiene la significación de un nombre; pues tales son ser, existencia, afirmación, movimiento, etc. (Noboa, 1839: 57).

Una manifestación de la influencia racionalista es la teoría del verbo único. Una cadena iniciada por Aristóteles y continuada por los "modistas" y algunos tratadistas renacentistas cristaliza en Port-Royal. Según esta teoría, fundamentada en la no distinción entre "juicio" (acto interior del espíritu) y "proposición" (expresión verbal del juicio), entre lenguaje y pensamiento, en definitiva, todos los verbos pueden ser reductibles a ser más otro elemento $y$, en consecuencia, toda proposición consta de "sujeto" + "verbo ser" + "atributo". Tal teoría tuvo defensores y detractores entre nosotros. No faltaron autores que incurren en contradicciones al mezclar lo tradicional de las definiciones semánticas con "lo moderno" francés (Jovellanos, 1795; Pelegrín, 1825).

En poco difiere la segunda etapa, la definición de tiempo verbal se basa fundamentalmente en el punto de vista semántico-nocional, en muchos casos acompañados por indicaciones sobre la forma: "... la desinencia que sufre la raíz verbal, para denotar el lugar que ocupa en la duración el fenómeno afirmado por la significación del verbo” (Fernández Monje, 1854: 124); “(...) fija la época en que tiene lugar la acción del verbo" (Ruiz Morote, 1880: 29); "Son tiempos del verbo las épocas en que se ejecuta la acción que el mismo verbo expresa" (Yeves, 1917: 20). Con algunos referentes coexistentes (“...el cambio que sufre el verbo en su terminación o letras finales, para expresar si su significado se refiere al acto de dirigir la palabra, o a una época anterior o posterior" (Boned, 1853: 18)) serán Bello y, más tarde, Lenz quienes introduzcan el concepto de punto de referencia (la deixis temporal) de manera sistemática: “(...) el ser ahora, antes o después, con respecto al momento mismo en que se habla" (Bello, 1847: 39); “Tiempo es la categoría gramatical por la cual la persona que habla establece una relación entre el fenómeno del cual habla y el acto de la palabra" (Lenz, 1920: 470).

Queremos centrar en este trabajo toda nuestra atención en dos gramáticos: uno de ellos de sobra conocido e importante en la 
historia de la gramática del español: Andrés Bello y otro, creemos, un descubrimiento: Gómez Hermosilla. Ambos adelantan las dos teorías más importantes de acercamiento al fenómeno de la llamada temporalidad. Con Bello la deixis temporal del verbo (Bull, 1947, 1960; Rojo, 1974, 1976, 1988, 1990; Rojo, Veiga, 1999) y la influencia del aspecto léxico interno del verbo con Gómez Hermosilla (Vendler, 1967; Verkuyl, 1993; Comrie, 1976, 1981, 1985, 1993; de Miguel, 1992, 1996, 1999)1.

\section{2.}

\section{Gómez Hermosilla (1835)}

Por el valor que tuvo en su contexto histórico-gramatical, por el esfuerzo personal que representa y por su propia propuesta, creemos que conviene destacar la aportación de Gómez Hermosilla $(1835)^{2}$.

Este autor se opone rotundamente, con un sistema teórico serio, a la teoría del verbo único que conocía su momento de apogeo; afirma que lo básico en las lenguas son los verbos "activos", anteriores a los "adjetivos" en la génesis del lenguaje; no es posible encontrar una lengua sin verbos activos y, más importante aún, no todos los verbos activos pueden descomponerse en ser + adjetivo.

Empieza su obra con la siguiente cita:

El universo no nos presenta más que materia y movimiento. Por materia o cuerpos entendemos lo que es capaz de hacer cualquiera impresión en nuestros sentidos. Movimiento es el efecto por el cual se muda un cuerpo de lugar, esto es, ocupa sucesivamente diferentes partes del espacio o lo que es lo mismo, varía de distancia respecto de otros cuerpos. El movimiento es el que establece las relaciones que hay en nuestros órganos y los entes

1 Citamos los estudios ya considerados clásicos para ambos enfoques.

2 Citamos por la tercera edición de 1841. 
que existen dentro y fuera de nosotros (Chabaneau, Elementos de ciencias naturales, Tomo I, 2-3).

Entiende Gómez Hermosilla que el hombre, una vez conocidos los objetos materiales que le rodean, pudo observar que no todos ocupaban de continuo el mismo lugar ni estaban siempre en una misma actitud. Así, el perro salta es el puro movimiento, el caballo relincha es un movimiento interior que produce ruido, el sol calienta produce movimiento interno a través de sensaciones. La idea de movimiento exterior e interior es la que va a estar presente en su definición de verbo:

Estas palabras destinadas a significar tanto los movimientos que se obran fuera de nosotros, como los que de ellos resultan en nuestros sentidos, son las que en gramática se llaman verbos, como si dijésemos, las palabras por excelencia, porque, en efecto, son las más necesarias de todas para la enunciación del pensamiento (Gómez Hermosilla, 1841: 20).

En el apartado sobre los tiempos verbales, para él, entre todas las circunstancias de un movimiento la más interesante es la del tiempo en que se verifica y éste se determina de dos maneras, o fijando una época precisa, como ayer, hoy, mañana o indicando vagamente que el tiempo en que se ejecuta el movimiento coincide con el acto de la palabra, es anterior o posterior a él:

Las épocas fijas, como todas las demás circunstancias, se enuncian por los nombres de estas épocas precedidas de una preposición o por adverbios que envuelven ésta implícitamente. La indicación vaga de que el movimiento es actual, pasado o futuro pudiera también hacerse por medio de palabras sueltas que significasen épocas indeterminadas ahora, antes de ahora, en adelante. Pero, siendo el tiempo, así vagamente considerado, una circunstancia inseparable de todo movimiento, y necesario por lo común expresarla, y debiendo ser incómodo repetir tan a menudo unas mismas palabras, el hombre, siempre ingenioso, imaginó el arbitrio de hacer en los verbos ciertas alteraciones 
materiales que indicases la circunstancia de ser el movimiento simultáneo, anterior o posterior respecto del momento en que se está hablando; y estas alteraciones son las que los gramáticos han llamado, con bastante propiedad, tiempos de los verbos, porque en efecto están destinadas a expresar la circunstancia del tiempo. Se ve, pues, que estos, en cualquiera lengua, son primitivamente tres, llamados presente, pretérito y futuro; porque, refiriendo el movimiento a la época de la palabra, ha de coincidir con ella, ha de ser anterior o posterior. Pero, como una época, ya pasada cuando hablamos, fue anterior, simultánea o posterior respecto de otra que se puede tomar por punto de comparación en toda la dirección corrida desde el origen del mundo, se ve que el pretérito puede subdividirse en tres épocas relativas, no ya al acto de la palabra sino a otro punto escogido en la duración pasada. La misma operación puede hacerse respecto del tiempo futuro. El que lo es ahora será, sin embargo, anterior, simultáneo o posterior, relativamente a otros puntos determinando que se toma en toda la duración venidera. El presente como es un momento indivisible, no es, ni puede ser más que uno porque todo lo que no es el instante actual pasó ya o no ha llegado todavía (Gómez Hermosilla, 1841: 108-110).

Hermosilla adelanta el sistema de deixis temporal:

Cada modo del verbo, según lo anterior, puede tener tres tiempos primitivos para expresar el momento que coincide con el momento en que se habla, le precedió o le seguirá. Estos se llaman presente, pretérito y futuro absoluto, porque no se refieren a otra época distinta del acto de la palabra. Además del pretérito y futuro absolutos puede haber tres pretéritos y tres futuros, relativos a un punto determinado que se escoja en la duración pasada y venidera, los cuales se denominarán en consecuencia pretéritos y futuros relativos (actuales, anteriores y posteriores) (Gómez Hermosilla, 1841: 111).

El gramático cae en la tentación de intentar una definición de verbo bajo un criterio semántico único. Fue muy criticado porque 
se basó en la génesis del lenguaje, en el significado primitivo de las acciones. Es una definición que se basa en el significado primitivo no en el actual y contemporáneo. Así, ante un verbo como sedeo, un verbo de quietud que significa estar sentado, Gómez Hermosilla (1841: 112) se explica diciendo que ahora significa quietud, pero que originariamente significó sentarse, donde sí hay verdadero movimiento. Esta caracterización lo lleva a establecer una distinción entre los verbos y los sustantivos que indican movimiento: los sustantivos que indican movimiento significan acciones no concretas, separadas del momento de su ejecución; los verbos significan acciones concretas, consideradas en el acto de ejecutarse, haberse ejecutado ya o haberse de ejecutar; la distinción verbo/ sustantivo no solo es, por tanto, una oposición semántica en el contenido (acción concreta/acción no concreta), sino también en el modo de significar: el verbo significa con tiempo y el nombre significa con abstracción del tiempo. En el ejemplo que da, meditación significa acción, pero no referida al tiempo, frente a meditar, que se refiere al tiempo, y meditamos, que además se refiere a la persona.

De esta interpretación, hasta cierto punto revolucionaria, aunque no aceptable en su totalidad, nos parecen especialmente interesantes las ideas del verbo como "movimiento" y la argumentación desarrollada en torno a la conceptualización del "espacio" y su relación con el "tiempo". En ellas Gómez Hermosilla recoge, de algún modo, la herencia de El Brocense, para quien el tiempo más que un accidente temporal es la manera de significar: el verbo significa y co-significa tiempo.

Podemos afirmar, sin mucho riesgo de equivocación, que en el período al que nos estamos refiriendo no existen apenas aportaciones sistemáticas. Hay casi una obsesión por definir y definir, de forma deductiva, hipótesis-verificación, pero sí llegan a un análisis del verbo y su sistema. Solo Hermosilla, como ha quedado dicho, apunta hacia la modernidad. Aun así, el hecho de dar importancia a la semántica interna del verbo, es decir, aislar rasgos semánticos, se revela importante para un posterior estudio del sistema verbal, ya que la semántica interna de los verbos puede influir claramente en su significado temporal. 


\section{Andrés Bello (1847)}

La postura de Andrés Bello ha sido la más atendida y seguida por los diferentes gramáticos que se han ocupado de la estructura del sistema verbal español. Bello, antes de estructurar el sistema, parte de la distinción entre formas simples y compuestas, como se venía haciendo ya desde antes. Define primariamente las formas del verbo como "significativas de tiempo". Destaca, como elemento relevante, la inclusión del gerundio con una de las formas simples de estar dentro de las formas compuestas, también significativas de tiempo:

Las formas compuestas en que entra el gerundio no presentan ninguna dificultad, porque expresan el mismo tiempo que la forma simple del auxiliar: yo estoy temiendo, significa el mismo tiempo que yo temo. Hay a la verdad diferencia entre estoy temiendo y temo; la primera expresión significa un estado habitual o una duración algo larga (está siempre escribiendo, estuvo toda la noche escribiendo); pero ésta no es una diferencia de tiempo, en el sentido que dan a esta palabra los gramáticos, porque la época del temer es siempre un puro pretérito respecto del momento en que se habla, sea que se diga temí o estuve temiendo (Bello, 1847: 400).

Señala en las formas del verbo un significado fundamental, del cual derivan otros dos: el secundario y el metafórico, y observa algunos hechos que le impiden generalizar las definiciones. Así, hablando de la coexistencia del presente con el momento del habla:

Esta relación de coexistencia no consiste en que las dos duraciones principien y acaben a un tiempo; basta que el acto de la palabra coincida con un momento cualquiera de la duración del atributo, la cual, por consiguiente puede haber comenzado largo tiempo antes y continuar largo tiempo después. Por eso 
el presente es la forma que se emplea para expresar verdades eternas o de una duración indefinida (Bello, 1847: 400).

Bello está afirmando que debemos de tener en cuenta dos concepciones temporales en el presente: presente puntual y presente ampliado.

También advierte en el tiempo pasado algunas salvedades. En el caso del pretérito llama la atención sobre el significado de los verbos y los divide en desinentes (significado perfectivo) y permanentes (significado imperfectivo): "ser, ver, oír, son verbos permanentes porque sin embargo de la existencia, la visión o la audición sea desde el principio, puede seguir durando gran tiempo" (Bello, 1847: 401).

Y si a esta objeción del significado fundamental del pretérito, añadimos la objeción que hace sobre el copretérito: "En esta forma el atributo es, respecto de la cosa pasada con la cual coexiste, lo mismo que el presente respecto en que se habla, es decir, que la duración de la cosa pasada con que se le compara puede no ser más que una parte de la duración" (Bello, 1847: 401).

Está anticipando que también en el pasado existe una doble concepción temporal: pasado puntual y pasado ampliado. Algo que no ocurre en el futuro, sobre estas formas no pone ninguna excepción sobre su significado fundamental.

Admite Bello (1847) que las relaciones de tiempo pueden ser simples, dobles y triples. Los tiempos verbales fechan la acción del verbo en la línea del tiempo en relación con tres puntos distintos de referencia (no solo con dos, como pensaban los de Port-Royal y sus seguidores) conjugados entre sí:

$1^{\circ}$ punto de referencia: el instante de hablar, llamado presente respecto del cual es anterior el pretérito y posterior, el futuro (relaciones simples).

$2^{\circ}$ punto de referencia: cada uno de estos tres tiempos, con respecto a los cuales la acción puede ser anterior, coexistente o posterior (relaciones dobles).

$3^{\circ}$ punto de referencia: un tiempo ya relativo respecto al cual un nuevo tiempo significa anterioridad (relaciones triples). 
Respecto de los mencionados significados metafóricos, Bello (1847) supera el nivel de la frase para afirmar que existen discursos que al hablante le interesa "actualizar" antecediéndolos al presente. Cuando afirma

La relación de coexistencia tiene sobre las otras la ventaja de hacer más vivas las representaciones mentales; ella está asociada con las percepciones actuales, mientras que los pretéritos y los futuros lo están con los actos de la memoria que ve de lejos y como entre las sombras lo pasado, o del raciocinio, que vislumbra dudosamente el porvenir (Bello, 1847: 422)

está reconociendo dos espacios y dos grados de abstracción temporal diferentes por parte del hablante: el aquí y el allí y, por tanto, dando importancia al criterio de la percepción. Reconoce que en ocasiones el hablante sustituye la relación de la anterioridad por la coexistencia (expresamos con más viveza los recuerdos); ello supone un cambio temporal de la siguiente forma: se usa presente donde "propia y naturalmente" debería usarse pretérito o copretérito; se usa futuro donde debería usarse pospretérito; se usa antepresente donde debería usarse antepretérito y antecopretérito y se usa antefuturo donde debería usarse antepostpretérito.

La sustitución puede ocurrir en el campo de la posterioridad. El hablante acerca al ámbito de la coexistencia acontecimientos sobre los cuales no está muy seguro y con el matiz modal de la conjetura usa un futuro donde debería usarse un presente; usa un postpretérito donde debería usarse un copretérito o pretérito; usa un antefuturo donde debería usarse un antepresente y usa un antepostpretérito donde debería usarse un antecopretérito.

Notamos que hay una preeminencia de formas referidas al pasado (tiempo experimentado) frente al presente y futuro. En este sistema, fundamento de posteriores teorías basadas en la deixis temporal, el origen principal es el presente, los sub-orígenes, el pretérito y el futuro $y$, por último, encontramos el copretérito y el pospretérito, lo cual da pie a hablar de diferentes niveles temporales:

1. Presente: primario

2. Pretérito y futuro: secundarios 
3. Copretérito y pospretérito: terciarios

Respecto a la caracterización de los tiempos dejamos en el aire algunas preguntas:

1. ¿Qué diferencia hay entre pretérito y antepresente? Los dos son anteriores al presente.

2. El copretérito es simultáneo al pretérito ¿por qué no también al antepresente?

3. El antecopretérito es anterior al copretérito ¿por qué no también al antepresente y al pretérito?

4. El pospretérito es posterior al pretérito ¿por qué no también al copretérito y al antepresente?

De Bello nos quedamos con las siguientes ideas:

1) La concepción temporal no es lineal. Hay que hablar de redes temporales y niveles temporales.

2) La dimensión temporal se transforma, al menos metafóricamente, en espacial: ante-, pos-, co-, indican movimientos espaciales ("delante", "detrás", "al lado")

3) El grado de abstracción temporal por parte del hablante es más complicado para las formas que se sitúan en las relaciones temporales triples.

\section{4.}

\section{Conclusiones}

Queremos hacer hincapié en la enseñanza de la temporalidad en un futuro no muy lejano. Es muy discutido el acercamiento que se debe hacer en las clases de ELE (Español Lengua Extranjera). Proponemos una enseñanza de la temporalidad basada en la combinación de ambos elementos: la estaticidad y la dinamicidad, los tipos de movimiento expresados por la semántica interna verbal, la concepción multidimensional del tiempo y del espacio y la consideración del procesamiento del input con elementos simples como el aquí y el allí, el antes de aquí y antes de allí, el antes, ahora y después y el momento: en este momento, en ese momento, en aquel momento, antes de ese momento, después de ese momento, en ese momento y antes. 


\section{Referencias bibliográficas}

Bello, A. (1841[1972]), Análisis ideológica de los tiempos de la conjugación castellana, Valparaíso: Imprenta de M. Rivadeneyra, repr. facs. Caracas, Cromotip.

Bello, A. (1847 [1988]), Gramática de la lengua castellana destinada al uso de los americanos, I-II, estudio y edición de Ramón Trujillo, Madrid: Arco/Libros.

Boned, L. (1853), Curso de gramática. Acomodado a la capacidad $y$ desarrollo intelectual de los niños, Zaragoza: Impr. y libr. de Cristobal Justé y Olona.

Bull, W. (1947), "Modern Spanish Verb Frequencies”, Hispania, $30,4,451-466$.

Bull, W. (1960), Time, Tense and the Verb. A Study in Theoretical and Applied Linguistics with Particular Attention to Spanish, Berkeley-Los Ángeles: University of California Press.

Comrie, B. (1976), Aspect An Introduction to the Study of Verbal Aspect and Related Problems Cambridge: Cambridge University Press.

Comrie, B. (1981), "On Reichenbach's Approach to Tense", en R. A. Hendrik, C. S. Masek y M. F. Miller (eds.), Papers from the Seventeenth Regional Meeting of the Chicago Linguistic Society, 24-30.

Comrie, B. (1985), Tense, Cambridge: Cambridge University Press.

Comrie, B. (1993), "Towards a General Theory of Tense", en B. Lakshmi Bai y A. Mukherjee (eds.): Tense and Aspect in Indian Languages, Hyderabad, Centre of Advanced Study in Linguistics (Osmania University), Booklinks Corporation, 1-18.

Fernández Monje, I. (1854), Curso elemental de la lengua española, redactado con la posible sujección a los principios de la gramática general, Madrid: Libr. de D. León Pablo Villaverde.

Gómez Asencio, J. J. (1981), Gramática y categorías verbales en la tradición española (1771-1847), Salamanca: Universidad de Salamanca.

Gómez Asencio, J. J. (1985), Subclases de palabras en la tradición española (1771-1847), Salamanca, Universidad de Salamanca. 
Gómez Hermosilla, J. (1835 [1841]), Principios de gramática general, Madrid: Imprenta Nacional (3a edición).

Jovellanos, G.M. de (1795 [1924]), "Curso de humanidades castellanas", B.A.E., tomo 46 en Nocedal, C., Obras publicadas e inéditas, Tomo I, Madrid, 101-150.

Lenz, R. (1920 [1935]), La oración y sus partes, Madrid: Centro de Estudios Históricos, $3^{\mathrm{a}} \mathrm{ed}$.

Miguel, E. de (1992), El aspecto en la sintaxis del español: perfectividad e impersonalidad, Madrid: Ediciones de la Universidad Autónoma de Madrid.

Miguel, E. de (1996), "Nomina Infinitives in Spanish: An Aspectual Constraint", The Canadian Journal of Linguistics 41, 1, 29-53.

Miguel, E. de (1999): “El aspecto léxico”, en I. Bosque y V. Demonte (eds.) Gramática descriptiva de la lengua española, vol 2, Madrid: Espasa Calpe, 2979-3060.

Noboa, D. A. M., (1839), Nueva gramática de la lengua castellana según los principios de la filosofía gramatical, Madrid: Impr. de D. Eusebio Aguado.

Pelegrín, L. (1825), Elementos de gramática universal, aplicados a la lengua española, Marsella: Impr. d'Achard.

Real Academia Española (1771), Gramática de la lengua castellana, Madrid: Impr. de D. Joaquín de Ibarra.

Rojo, G. (1974), "La temporalidad verbal en español", Verba 1, 68-149.

Rojo, G. (1976), “La correlación temporal”, Verba 3, 65-89.

Rojo, G. (1988), “Temporalidad y aspecto en el verbo español”, LEA, X, 195-216.

Rojo, G. (1990), "Relaciones entre temporalidad y aspecto en el verbo español”, en I. Bosque (ed.), Tiempo y aspecto en español, Madrid, Cátedra, 17-41.

Rojo, G. y Veiga, A.(1999), “El tiempo verbal. Los tiempos simples”, en I. Bosque y V. Demonte (eds.) Gramática descriptiva de la lengua española, Vol. 2, Madrid: Espasa Calpe, 2867-2935.

Ruiz Morote, F. (1880), Gramática castellana teórico-práctica, premiada en las exposiciones aragonesa, Viena y Madrid, Ciudad Real: Establecimiento tipogr. del Hospicio, $6^{\mathrm{a}}$ ed. corregida y metodizada. 
Vendler, Z. (1967), Linguistics in Philosiphy, Ithaca: Cornell University Press.

Verkuyl, H. (1993), A Theory of Aspectuality. The Interaction between Temporal and Atempotal Structure, Cambridge: Cambridge University Press.

Yeves, C. (1917), Gramática castellana. Grado primero. Conocimiento general de las palabras y de sus accidentes, Madrid: Libr. de los sucesores de Hernando. 